\title{
Electric three-wheelers as an alternative to combustion-engined autorickshaws in Dar es Salaam - Generation of a standard drive cycle, Power Train modelling and simulation of the energy demand of light electric vehicles
}

\author{
Christian Wachter \\ Martin Schüttoff \\ Frank Rinderknecht
}

German Aerospace Center

Institute of Vehicle Concepts

Pfaffenwaldring 38-40

70569 Stuttgart, Germany

christian.wachter@dlr.de martin.schuettoff@gmail.com

frank.rinderknecht@dlr.de

\author{
Mirko Goletz \\ Daniel Ehebrecht \\ Barbara Lenz
}

\author{
Meike Kühnel
Benedikt Hanke \\ Meike Kühnel
Benedikt Hanke
}

German Aerospace Center Institute of Networked Energy Systems

Carl-von-Ossietzky-Straße 15

26129 Oldenburg, Germany

meike.kuehnel@dlr.de benedikt.hanke@dlr.de

\begin{abstract}
This study analyses the feasibility of electric 3-wheeled motorcycle-taxis in Dar es Salaam from a technical and user-oriented point of view on the power train. Based on the experiences and expectations of an interviewed group of drivers, two electric power train variants for 3-wheeled vehicles have been set up and compared. In order to calculate the vehicle energy demand, a simulation model has been set up. This model uses a drive cycle that has been generated for the specific location of Dar es Salaam using GPS tracks recorded during a field trip. Results contain the vehicle battery weight, energy demand and range for varied battery capacities. Finally, a possible power train variant is suggested.
\end{abstract}

Keywords - light electric vehicle, three-wheeler, autorickshaw, electric power train, standard drive cycle, power train modelling, energy demand, Dar es Salaam, Tanzania

\section{INTRODUCTION}

Two and three wheeled motorcycle taxis have a significant and increasing modal share in rural and urban areas of developing countries, especially in Sub-Saharan Africa [1]-[3]. Driven by small combustion engines, those vehicles contribute to air pollution in those countries [4], [5].
In Dar es Salaam, Tanzania's largest city, three wheelers play an important role as a de-facto public transport connecting main roads with residential areas as well as feeding the public transport system [6].

In 2014, over 50,000 three wheelers were registered in Tanzania with an ongoing strong growth in numbers [7]. In an attempt to regulate this informal public transport sector, a law was amended in 2010 in order to legalize the motorcycle taxis [8], but they were also banned from the city center to, among other reasons, improve air quality ${ }^{1}$.

Being locally emission free and quiet, electric 3wheelers could be a promising solution to face these challenges. However, electric 3-wheelers need to be accepted by both drivers and passengers in terms of usability, range, reliability, safety, maintenance and energy costs. Especially regarding costs, the vehicle market in Tanzania is highly sensitive [9]. Hence, a shift from fuel to electric driven vehicles can only be expected if the life cycle costs of the electric vehicles are equal or lower than those of their fuel pendants.

This study analyzes the feasibility of electric 3wheeled motor taxis in Dar es Salaam from a technical and user-oriented point of view on the power train.

\footnotetext{
${ }^{1}$ According to local stakeholders interviewed in March 2018 and February 2019.
} 


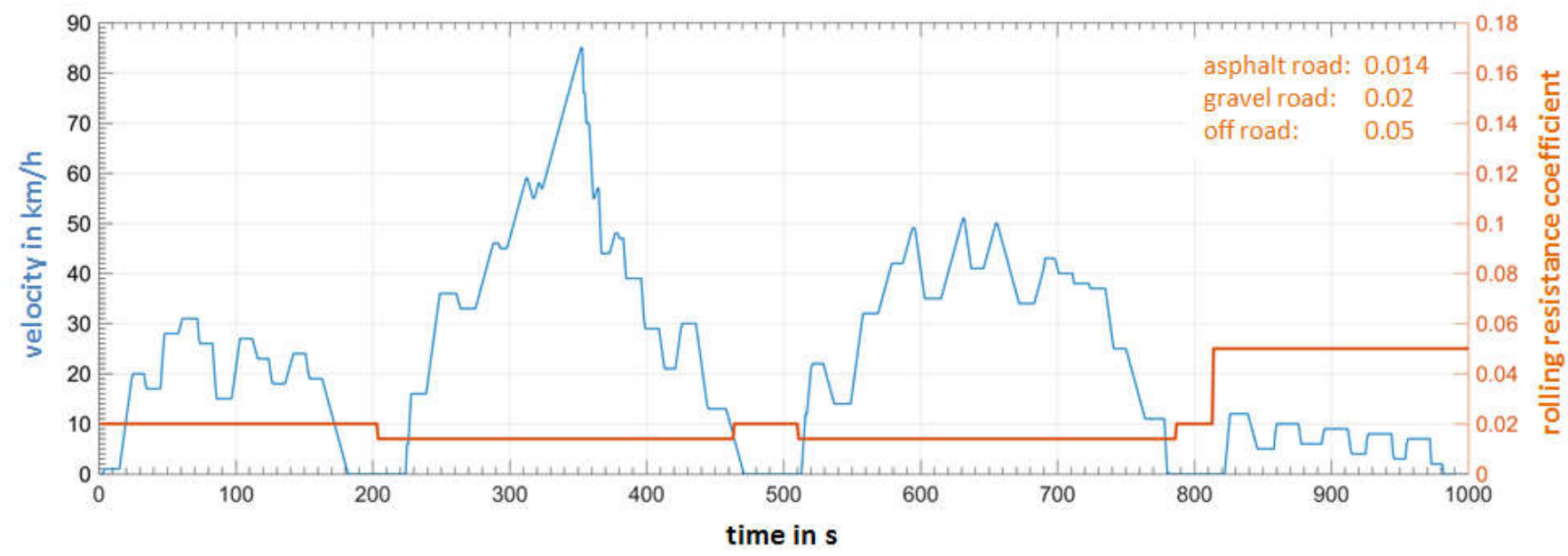

Figure 1: Generated drive cycle for an average 3-wheeler trip in Dar es Salaam, Tanzania

Therefore, a user-centered approach has been chosen, which draws conclusions from simulations of an electric 3 -wheelers range with the perception of interviewed taxi drivers on expected benefits and challenges.

\section{APPROACH}

In two field trips to Dar es Salaam in November/December 2018 and February 2019 interviews with groups of 3-wheel motor taxi drivers have been conducted. Asked about their expectations if switching to electric driven vehicles, the drivers see mainly benefits, such as better acceleration capability, lower maintenance and energy costs as well as bigger appeal to potential customers. However, taxi business in Tanzania is a very cost sensitive market [9]. With fuel driven vehicles starting from a price tag of 2700-3500\$, drivers state that an electric driven vehicle has to be in the same range or not much above, given that maintenance and/or energy costs turn out to be lower during lifetime. This means that the powertrain of an electric 3-wheeler needs to be designed with rather low-priced but reliable components. As can be expected, the biggest cost driver is the battery, depending on the required capacity.

Two variants of possible power trains have been considered. A more advanced variant with lithium ion battery and a $400 \mathrm{~V}$ intermediate circuit that leads to a lower overall weight of the vehicle. The second one being a low-cost variant with lead acid battery and a $48 \mathrm{~V}$ intermediate circuit that would allow to use standard car batteries, but leads to a considerably higher weight. For the $400 \mathrm{~V}$ variant an IGBT inverter was considered as well as an asynchronous motor with $20 \mathrm{~kW}$, while for $48 \mathrm{~V}$ a MOSFET inverter with a low voltage asynchronous motor (20kW as well) has been found to be more suitable. Both inverters show a similar efficiency at their specific voltage range as do the motors. The remaining component is equal for both variants: a gearbox with two stages that has been optimized in order to allow the electric machine to turn at $10.000 \mathrm{rev} / \mathrm{min}$ at an intended top speed of 90 $\mathrm{km} / \mathrm{h}$.

In order to calculate the range of a virtual electric 3wheeler, a simulation model has been built up which calculates the energy demand while driving a given drive cycle. With the vehicle's current velocity, the mechanical or electrical power starting from the wheels to gear box, electric motor and inverter up to the intermediate circuit, the energy demand can be calculated for every time step in the drive cycle. For every component the efficiency is modelled by either an efficiency map or a fixed efficiency. The battery with its varying efficiency depending on the state of charge has been left out in this model to reduce complexity. Therefore, the energy demand of the vehicle is the one at the intermediate circuit. Regarding energy recuperation, the model balances deceleration power as negative, as long as it is below the power of the electric machine. Otherwise the portion being above is assumed to be taken by the mechanical brakes.

Usually, the energy demand of a vehicle is determined by using a standard drive cycle such as the Worldwide harmonized Light Duty Test Cycle (WLTC). However, the usage of 3-wheel taxis during the field trip in Dar es Salaam gave the impression, that those standard cycles do not come close to the real usage of the vehicles and therefore would lead to a non-representative energy demand. From the first field trip in 2018 a huge data base of GPS-tracked ${ }^{2}$ vehicle trips was available, containing trips from 65 vehicles tracked during 4 weeks. Being the most common and typical trip length, all trips from $1-5 \mathrm{~km}$ have been analyzed by counting the numbers of constant

\footnotetext{
${ }^{2}$ GPS tracking was conducted using the Moving Lab (movinglab.dlr.de).
} 
velocity, acceleration and deceleration points in the trips. Partly following the approach of Eghtessad [10], an artificial test cycle has been generated reflecting the percentage of the counted velocities and accelerations and thereby representing an average 3-wheeler trip in Dar es Salaam, Tanzania.

\section{RESULTS AND DISCUSSION}

The generated drive cycle is shown in Figure 1. The length has been set to $1000 \mathrm{sec}$ in order to make it easily comparable to the WLTC. It has been purposely separated into four sections, which represent typical driving situations. To reflect the different road conditions, the rolling resistance coefficient is varied automatically depending on the mean speed of a section. The first section represents a trip from a residential area to a main road that for example could feed the public bus rapid transit (BRT) system. The roads in residential areas are mainly small and gravel roads, which results in a maximum speed of $31 \mathrm{~km} / \mathrm{h}$. The second section is a trip on an asphalted main road from the suburbs to the city center. Here, higher speeds up $86 \mathrm{~km} / \mathrm{h}$ have been measured. Despite such high speeds represent a very small portion in the measured trips, such a high maximum speed has been added on drivers' demand who wish for a fast vehicle. The third section is a trip inside the city center with a limited maximum speed of $52 \mathrm{~km} / \mathrm{h}$ on asphalted roads. The last section is a trip through a residential area with a very bumpy dirt road. To model the higher energy demand for that kind of road, the rolling resistance coefficient has been significantly increased.

Figure 2 shows the simulation results for a vehicle with full load $(300 \mathrm{~kg}$, equals approx. one driver plus three passengers) or half load (150kg, one driver plus one passenger). The simulation has been conducted for a vehicle using lead acid or lithium ion batteries which leads to a different overall weight of the vehicle. Battery size has been varied in steps of $2 \mathrm{kWh}$ in a range from 4 to $16 \mathrm{kWh}$.

The generated cycle (Figure 1) is performed one time by the simulation model with the chosen vehicle parameters and the mean energy demand is calculated. Accordingly, the vehicles range is calculated with the corresponding battery capacity. Therefore, all battery capacities given here are net capacities.

Whereas energy demand and vehicle range do not differ much with the increasing battery weight difference between the two variants due to the vehicles recuperation capability while braking, the difference in battery weight widens strongly with increasing capacity.
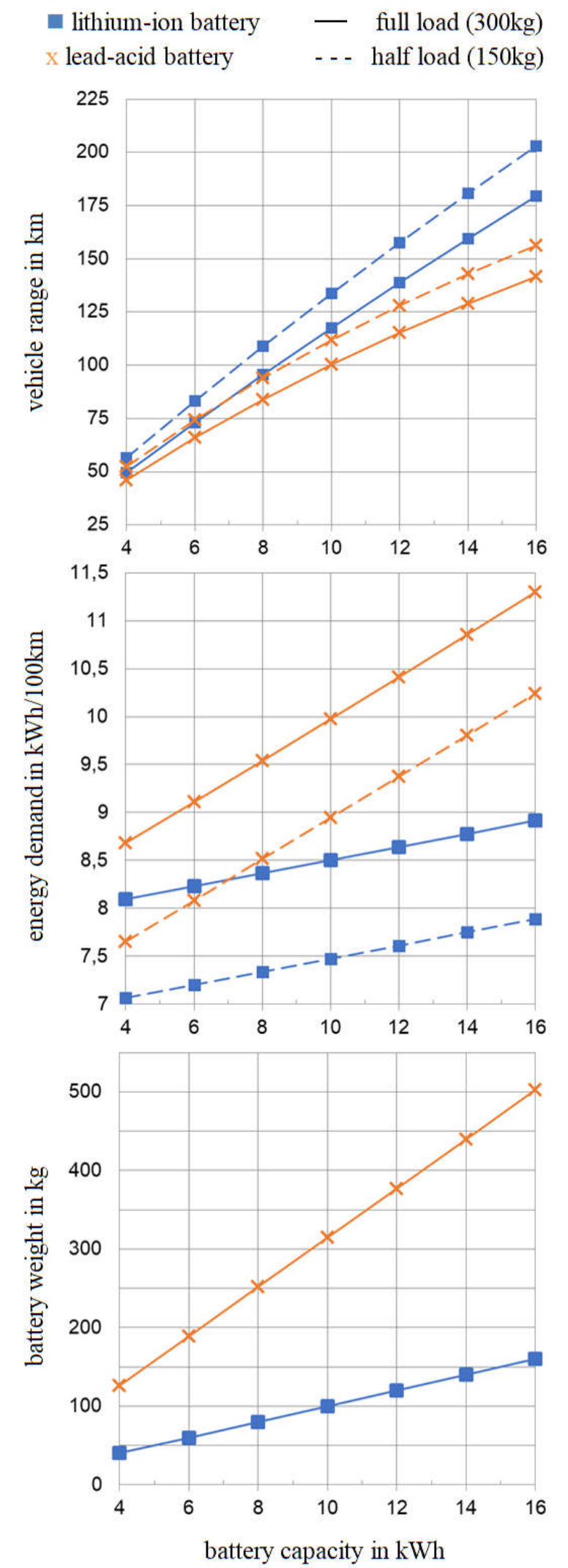

Figure 2: Battery weight, energy demand and vehicle range for different battery capacities of a 3 -wheeler. 
For the lead acid variant this would lead to the need for a stronger chassis, at least above a certain battery weight. This effect, which has not been included in the model, would widen the gap even more.

To examine the effect of recuperation, three simulation runs have been carried out as follows: with recuperation as described above for two electric motors with $10 \mathrm{~kW}$ and $20 \mathrm{~kW}$ power and with no recuperation at all. The remaining vehicle parameters were constant for all three runs using the battery weight of a $10 \mathrm{kWh}$ lithium ion battery. Table 1 shows the corresponding values for the vehicle's energy demand:

Table 1: Energy demand with and without recuperation for a fully loaded vehicle $(300 \mathrm{~kg})$ with a $10 \mathrm{kWh}$ lithium ion battery

\begin{tabular}{|l|c|}
\cline { 2 - 2 } \multicolumn{1}{c|}{} & $\begin{array}{c}\text { energy demand } \\
\text { in } \mathrm{kWh} / 100 \mathrm{~km}\end{array}$ \\
\hline without recuperation & 9,51 \\
\hline with $\mathrm{P}_{\mathrm{EM}}=10 \mathrm{~kW}$ & 8,62 \\
\hline with $\mathrm{P}_{\mathrm{EM}}=20 \mathrm{~kW}$ & 8,50 \\
\hline
\end{tabular}

The results suggest that recuperation should be used as otherwise the vehicles range would drop, while the cost of the power electronics becomes only slightly higher in order to enable it to recuperate. Due to the characteristics of the drive cycle, there is only a minor difference between the two motor variants. Therefore, a small percentage of range could be sacrificed in favor of a lower priced electric motor. However, for the use case presented here, using a $20 \mathrm{~kW}$ electric motor is necessary in order to reach the cycle's top speed of $86 \mathrm{~km} / \mathrm{h}$ which was the highest measured speed in the GPS tracked data. The effect of the vehicles top speed has been examined, too, as shown in Figure 3. For these simulation runs, the weights of a 10kWh lithium ion or lead acid battery have been used and the cycle's top speed has been cut to the specified values. As expected, the top speed has a great influence on the vehicle's energy demand in the drive cycle, mainly due to the necessary energy for acceleration and the higher aerodynamic resistance at higher velocities.

This effect also shows up when comparing the vehicles energy demand in the generated Dar es Salaam-cycle with the standard WLTC class 1 cycle. Again, the parameters for a fully loaded vehicle with a $10 \mathrm{kWh}$ lithium ion battery have been used. As the values in Table 2 point out, the energy demand for the WLTCcycle is slightly higher, which results from a higher percentage of velocities above $50 \mathrm{~km} / \mathrm{h}$, where the effect of aerodynamic resistance becomes dominant.
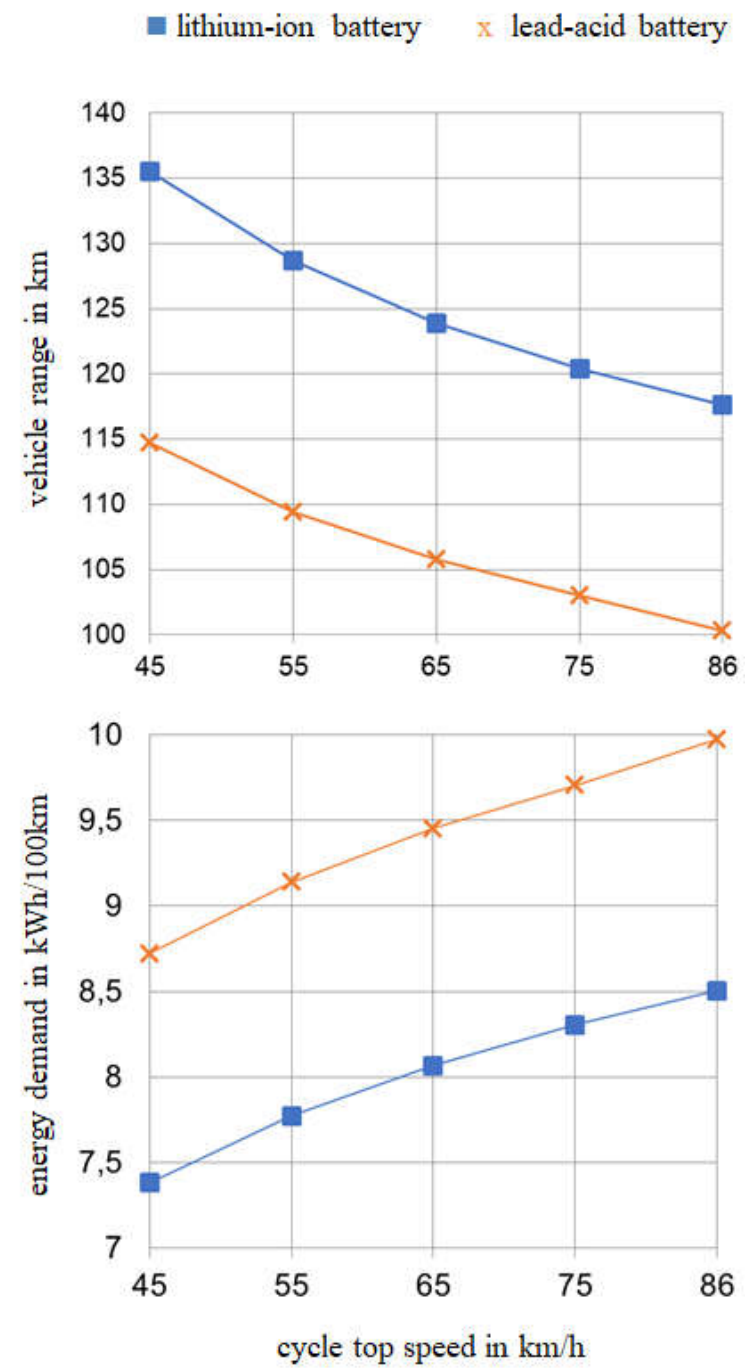

Figure 3: Vehicle's range and energy demand depending on the cycle's top speed (10kWh lithium ion battery, full load of $300 \mathrm{~kg}$ )

This is quite interesting since real drives usually show a higher energy demand than artificial test cycles. Nonetheless this corresponds to the experiences made during the field trip: in Dar es Salaams traffic, especially at rush hour, velocities of $50 \mathrm{~km} / \mathrm{h}$ and above are seldom reached.

Table 2: Energy demand for Dar es Salaam- and WLTC class 1-cycle

(fully loaded vehicle $300 \mathrm{~kg}$, 10kWh lithium ion battery)

\begin{tabular}{|l|c|}
\cline { 2 - 2 } \multicolumn{1}{c|}{} & $\begin{array}{c}\text { energy demand } \\
\text { in } \mathrm{kWh} / 100 \mathrm{~km}\end{array}$ \\
\hline Dar es Salaam-cycle & 8,50 \\
\hline WLTC class 1 cycle & 8,94 \\
\hline
\end{tabular}




\section{CONCLUSION}

Comparing the two power train variants, the specific components show a roughly similar efficiency regardless of the intermediate circuit voltage. The difference in energy demand is caused by the different weight of the battery packs. The authors conclude that for a battery capacity demand up to $8 \mathrm{kWh}$ lead acid batteries can be considered a worthwhile alternative due to benefits like lower price and good availability in developing countries. Above $8 \mathrm{kWh}$ lithium ion batteries seem to be without alternative due to their higher energy density. Especially if considering retrofitting existing vehicles, the weight of the electric power train is critical in order to meet the load capacity of the existing chassis.

To get a final statement, the actual needed battery capacity for the investigated use case needs to be determined, which is done in a corresponding study [11]. This study investigates typical trip lengths, pauses and their distribution over the day, possible locations for charging infrastructure and the effect of opportunity charging. In order to serve $75 \%$ of the use cases, the authors find that a lithium ion battery has to deliver 4.95/9.2kWh (with/without opportunity charging) and a lead acid battery $6 / 11.5 \mathrm{kWh}$. Combined with the results of the study at hand, a range of around $90 \mathrm{~km}$ will be sufficient for a fully loaded vehicle with opportunity charging. For a fully loaded vehicle without opportunity charging, the range has to be around $150 \mathrm{~km}$ in order to cover a full work day.

As the authors rate safety a high issue in developing countries, a $48 \mathrm{~V}$ intermediate circuit voltage is favored. Regarding battery technology, lithium ion batteries are recommended, at least in the medium term. Consequently, for future investigations a power train with lithium ion batteries on a $48 \mathrm{~V}$ level will be examined.

Current studies predict that lithium ion battery pack prices will drop more than $50 \%$ until 2030 , leading to estimated prices between $75 € / \mathrm{kWh}$ [12] and $84 € / \mathrm{kWh}$ [13]. For our case, this would lead to a price of $500 €$ (6kWh, 90km range) or $840 €(10 \mathrm{kWh}, 150 \mathrm{~km}$ range) for the battery pack.

Combined with lower maintenance needs and energy costs, electric 3-wheelers can become competitive to their fuel driven equivalents within the next $10-15$ years.

\section{ACKNOWLEDGMENT}

The authors give special thanks to the Bajaj drivers for taking part in the surveys and the GPS tracking. The authors thank the German Aerospace Center (DLR) for the funding of the project activities.

\section{REFERENCES}

[1] L. Diaz Olvera, D. Plat, D. Pochet, M. Sahabana, "Motorized Two-Wheelers in Sub-Saharan African Cities: Public and Private Use". Paper presented at the 12th World Conference on Transport Research, 11-15 July 2010, Lisbon, Portugal.

[2] D. Ehebrecht, D. Heinrichs, B. Lenz, "Motorcycle-taxis in subSaharan Africa: Current knowledge, implications for the debate on "informal" transport and research needs". Journal of Transport Geography, Vol. 69, pp. 242-256. 2018.

[3] P. Starkey, "The Benefits and Challenges of Increasing Motorcycle Use for Rural Access". Paper presented at the International Conference on Transport and Road Research, 1618 March 2016, Mombasa, Kenya.

[4] C.M. Adiang, D. Monkam, E. Njeugna, S. Gokhale, "Projecting Impacts of Two-Wheelers on Urban Air Quality of Douala, Cameroon”. Transportation Research Part D 52, pp.49-63. 2017.

[5] M. G. Badami, "Transport and Urban Air Pollution in India". in Environmental Management, B. Brooks, 36. Edition: Springer US, 2005 (2), page 195-204.

[6] M. Goletz and D. Ehebrecht, "How Can GPS/GNSS Tracking Data $\mathrm{Be}$ Used to Improve Our Understanding of Informal Transport? A Discussion based on a Feasibility Study from Dar es Salaam". Journal of Transport Geography (in press). 2018.

[7] T. Bishop, P. Amos, "Opportunities to Improve Road Safety Through 'Boda-Boda' Associations in Tanzania". Final Report. Thame, UK: AFCAP/ASCAP Project Management Unit, Cardno Emerging Market (UK) Ltd. p. 16, 2015.

[8] Republic of Tanzania, The Transport Licensing (Motor Cycles and Tricycles) Regulations 2010.

[9] H. Edinger, K. Mc Donald, S. Schaefer, „Africa Automotive Insights - An East African consumer perspective". Brochure, 2018.[Online].

https://www2.deloitte.com/content/dam/Deloitte/ug/Documents/ consumer-business/ea_2018-A-Consumer-Perspective-Auto.pdf

[10] M. Eghtessad, „Optimale Antriebsstrangkonfigurationen für Elektrofahrzeuge“. Ph.D. dissertation, Technische Universität Braunschweig, Schriftenreihe des Instituts für Fahrzeugtechnik, TU Braunschweig 35, ISBN: 978-3-8440-2782-2. 2014

[11] B. Hanke, M. Kühnel, B. Nickel, D. Tolk, K. von Maydell, C. Agert, M. Goletz, D. Ehebrecht, B. Lenz, C. Wachter, F. Rinderknecht , Interdependence of charging infrastructure and battery demand of light electric 3-wheel motor taxis". EVER 2020, Monaco, May 2020, Topic EV4-b Conductive/inductive charging infrastructure.

[12] M. Ierides, R. del Valle, D. Fernandez, L. Bax, P. Jacques, F. Stassin, and M. Meeus, "Advanced Materials for Clean and Sustainable Energy and Mobility - EMIRI key R\&I priorities," Energy Materials Industrial Research Initiative (EMIRI) Technology Roadmap, p. 292, Sept. 2019.

[13] "Battery requirements for future automotive applications" European Council for Automotive R\&D (eucar), p. 4, https://www.eucar.be/battery-requirements-for-futureautomotive-applications/, Aug. 2019. 